\title{
A presença de estudantes indígenas na educação profissional e tecnológica
}

\section{The presence of indigenous students in vocational and technological education}

\section{La presencia de estudiantes indígenas en la educación profesional y tecnológica}

\author{
Juliana da CRUZ MÜLling ${ }^{1} 1$ \\ Simone VAldete Dos SANTOS $\circledast^{2}$ \\ ${ }^{1}$ Instituto Federal de Educação, Ciência e Tecnologia do Rio Grande do Sul, Canoas, RS, Brasil. \\ ${ }^{2}$ Universidade Federal do Rio Grande do Sul, Porto Alegre, RS, Brasil.
}

\begin{abstract}
RESUMO
A presença de estudantes indígenas e da sua cultura específica, no âmbito da Rede Federal de Educação Profissional, é ainda recente, considerando a expansão dos Institutos Federais de Educação Profissional, Ciência e Tecnologia e a implementação da Lei de Cotas no 12.711 , de 2012. A pesquisa desenvolvida apresenta o mapeamento das terras indígenas demarcadas e dos campi dos Institutos Federais presentes no Rio Grande do Sul, bem como o número de matrículas de estudantes indígenas em cada campus. No campus Sertão do Instituto Federal do Rio Grande do Sul, evidenciou-se a presença significativa de estudantes indígenas. A metodologia da pesquisa baseou-se em entrevistas etnográficas junto a gestores, técnicos administrativos, professores e estudantes indígenas kaingang. Foram identificadas implicações da presença kaingang nos processos burocráticos e pedagógicos da instituição.

Palavras-chave: Educação profissional. Educação indígena. Interculturalidade.
\end{abstract}

\begin{abstract}
The presence of indigenous students and their specific culture within the federal system of Vocational Education is still recent, considering the expansion of the Federal Institutes of Vocational Education, Science and Technology and the implementation of the Law of Quotas No. 12711 of 2012. The developed research presents the mapping of the demarcated indigenous lands and the campuses of the Federal Institutes present in Rio Grande do Sul, Brazil, as well as the number of indigenous student enrollments in each campus. In the Sertão campus of the Federal Institute of Rio Grande do Sul, there was a significant attendance of indigenous students. The research methodology was based on ethnographic interviews with managers, administrative staff, teachers and indigenous Kaingang students. Implications of the presence of the Kaingangs were identified in the institution's bureaucratic and pedagogical processes.
\end{abstract}

Keywords: Vocational education. Indigenous education. Interculturality.

\section{RESUMEN}

La presencia de estudiantes indígenas y su cultura específica, en el ámbito de la red federal de Educación Profesional, es todavía reciente, considerando la expansión de los Institutos Federales de Educación Profesional, Ciencia y Tecnología y la implementación de la Ley de Cuotas no 12.711, de 2012. A la investigación desarrollada presenta el mapeamiento de las tierras indígenas demarcadas y de los campus de los Institutos Federales presentes en Rio Grande do Sul, así como el número de matrículas de estudiantes indígenas en cada campus. En el campus Sertão del Instituto Federal de Rio Grande do Sul, se evidenció la presencia significativa de estudiantes indígenas. La metodología de la investigación se basó en entrevistas etnográficas junto a gestores, técnicos administrativos, profesores y estudiantes indígenas kaingang. Se identificaron implicaciones de la presencia kaingang en los procesos burocráticos y pedagógicos de la institución.

Palabras clave: Educación profesional. Educación indígena. Interculturalidad. 


\section{INTRODUÇÃo}

A educação profissional para os indígenas no Brasil tem a marca da exploração da mão de obra e da grilagem de terras pela sociedade envolvente. A tese de doutorado de Bringmann (2015) relata o quanto a atuação do Serviço de Proteção ao Índio (SPI) no período de 1941 a 1967 serviu para reforçar a perda do idioma, a substituição dos modos tradicionais de cultivo e de alimentação, desestabilizando o modo de ser dos kaingang, etnia envolvida na pesquisa em tela.

Os Institutos Federais de Educação, Ciência e Tecnologia são instituições de constituição recente e, desde a aprovação da Lei no 11.892 (BRASIL, 2008), integram a Rede Federal de Educação Profissional, Científica e Tecnológica junto dos Centros Federais de Educação Tecnológica (CEFETs), das Escolas Agrotécnicas Federais, das Escolas Técnicas Vinculadas às Universidades Federais, do Colégio Pedro II e da Universidade Tecnológica do Paraná. A Rede Federal desenvolve atividades de ensino de formação inicial e continuada de educação profissional, ensino técnico integrado ao ensino médio, também cursos ${ }^{1}$ concomitantes, subsequentes e integrados à educação de jovens e adultos, cursos superiores de licenciatura para formação de professores, tecnólogos e pós-graduação, bem como pesquisa e extensão.
A centralidade da presente análise corresponde às formas de acesso e acolhimento aos estudantes indígenas que têm procurado pela educação profissional na Rede Federal do Estado do Rio Grande do Sul, sendo realizado inicialmente o mapeamento das instituições cuja localidade se aproxima das terras indígenas demarcadas. Esse mapeamento situou como de maior proximidade geográfica para os territórios indígenas o Instituto Federal do Rio Grande do Sul (IFRS) e o Instituto Federal Farroupilha (IFFar), nos quais realizou-se o levantamento das matrículas ativas de estudantes indígenas e, posteriormente, um estudo aprofundado na experiência do Campus Sertão do Instituto Federal de Educação, Ciência e Tecnologia do Rio Grande do Sul (IFRS). Essa é uma instituição representativa em virtude do número de estudantes indígenas presentes em seu campus e pela proposta diferenciada do acesso e do acompanhamento aos estudantes indígenas.

\section{MATRÍCULAS DE ESTUDANTES INDÍGENAS NOS CAMPI DO IFFAR E DO IFRS}

Primeiramente, optamos por iniciar o levantamento dos dados referentes ao ingresso indígena no Instituto Federal do Rio Grande do Sul (IFRS) e no Instituto Federal Farroupilha (IFFar), como informado anteriormente, em virtude da proximidade dessas instituições com os maiores territórios indígenas demarcados no Estado (Figura 1).

Figura 1 - Mapeamento das terras indígenas demarcadas e dos campi da Rede Federal do Rio Grande do Sul

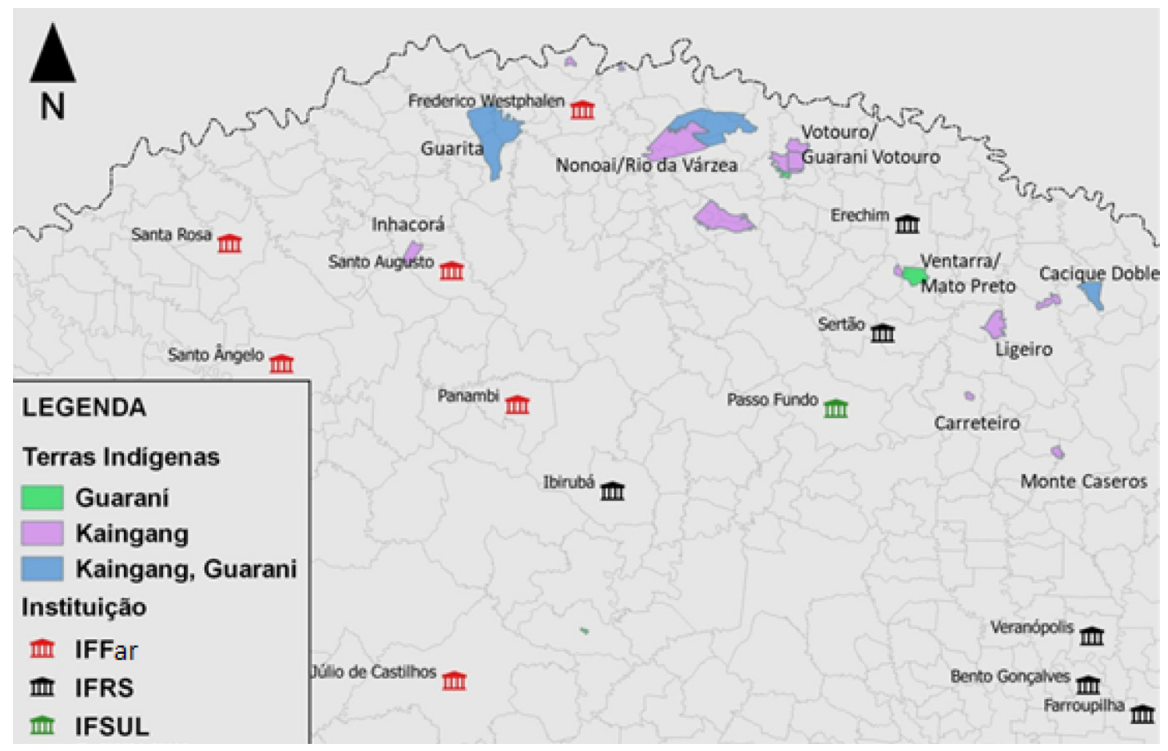

Fonte: MÜLLING (2018)

\footnotetext{
${ }^{1}$ Conforme o parecer 11 do Conselho Nacional de Educação (BRASIL, 2012b, p. 41-42), a oferta dos cursos técnicos ocorrem nos seguintes formatos : integrada com o ensino médio no âmbito do PROEJA(Programa Nacional de Integração da Educação Profissional com a Educação Básica na Modalidade de Educação de Jovens e Adultos regulamentado pelo Decreto n. $\left.{ }^{\circ} 5.840 / 2006\right)$, a oferta concomitante com o ensino médio
}

regular, na mesma instituição de ensino ou em instituições de ensino distintas, aproveitando-se as oportunidades educacionais disponíveis; a oferta subsequente educação profissional técnica de nível médio ofertada após a conclusão do ensino médio regular ou na modalidade de EJA e a oferta integrada com o ensino médio regularmente oferecido, na idade própria, no mesmo estabelecimento de ensino. 
Entramos em contato com as unidades acadêmicas do IFFar e do IFRS através de seus endereços eletrônicos institucionais, solicitamos o número de estudantes matriculados em cada curso técnico de nível médio de seu cada um de seus campi.
Do retorno obtido, constam os dados obtidos no Quadros 1 e no Quadro 2).

Diante dos Quadros 1 e 2, é possível observar que o atendimento às comunidades indígenas pelos cursos ofertados na Rede Federal é numericamente pouco significativo.

Quadro 1 - Matrículas de estudantes indígenas nos cursos técnicos de nível médio IFFar, de 2013 a 2016

\begin{tabular}{|l|c|l|l|l|}
\hline \multicolumn{5}{|c|}{ Instituto Federal Farroupilha } \\
\hline Campus & $\begin{array}{l}\text { Número de } \\
\text { Indígenas } \\
\text { (2013-2016) }\end{array}$ & $\begin{array}{l}\text { Cursos Técnicos que comportam as matrículas de } \\
\text { estudantes indígenas no período }\end{array}$ & Permanência & Evasão \\
\hline $\begin{array}{l}\text { Frederico } \\
\text { Westphalen }\end{array}$ & 5 & $\begin{array}{l}\text { Técnico em Informática Integrado ao Ensino Médio (2); } \\
\text { Técnico em Agropecuária Integrado ao Ensino Médio (3). }\end{array}$ & Permanecem 2 estudantes. & $\begin{array}{l}\text { Evadiram } \\
3 \text { estudantes. }\end{array}$ \\
\hline Jaguari & 2 & $\begin{array}{l}\text { Técnico em Agroindústria Integrado ao Ensino Médio (1); } \\
\text { Técnico em Agroindústria Integrado ao Ensino Médio - } \\
\text { Modalidade PROEJA (1). }\end{array}$ & $\begin{array}{l}\text { Permanece 1 estudante. } \\
\text { Evadido estudante do } \\
\text { PROEJA. }\end{array}$ & $\begin{array}{l}\text { Evadiu } \\
1 \text { estudante. }\end{array}$ \\
\hline Panambi & 3 & Técnico em Agricultura de Precisão (1); Edificações (2) & $\begin{array}{l}\text { Permanece 1 estudante no } \\
\text { Curso de Edificações. }\end{array}$ & $\begin{array}{l}\text { Evadiram } \\
2 \text { estudantes. }\end{array}$ \\
\hline
\end{tabular}

Fonte: MÜLLING (2018).

Quadro 2 - Matrículas de estudantes indígenas nos cursos técnicos de nível médio do IFRS, de 2013 a 2016

\begin{tabular}{|c|c|c|c|c|}
\hline \multicolumn{5}{|c|}{ Instituto Federal do Rio Grande do Sul } \\
\hline Campus & $\begin{array}{l}\text { Número de } \\
\text { Indígenas } \\
(\mathbf{2 0 1 3 - 2 0 1 6 )}\end{array}$ & $\begin{array}{l}\text { Cursos Técnicos que comportam as matrículas de } \\
\text { estudantes indígenas no período }\end{array}$ & Permanência & Evasão \\
\hline Erechim & 3 & $\begin{array}{l}\text { Técnico Subsequente em Logística (1); Técnico } \\
\text { Subsequente em Mecânica (1); Técnico Subsequente em } \\
\text { Modelagem e Vestuário (1). }\end{array}$ & Permanece 1 estudante.* & $\begin{array}{l}\text { Evadiram } \\
2 \text { estudantes. }\end{array}$ \\
\hline $\begin{array}{l}\text { Caxias do } \\
\text { Sul }\end{array}$ & 3 & $\begin{array}{l}\text { Técnico em Química Integrado ao Ensino Médio (1); } \\
\text { Técnico em Plásticos Integrado ao Ensino Médio (2). }\end{array}$ & \multicolumn{2}{|c|}{$\begin{array}{l}\text { Não obtivemos detalhamento sobre a situação } \\
\text { dos estudantes. }\end{array}$} \\
\hline Canoas & 8 & $\begin{array}{l}\text { Técnico em Informática Integrado ao Ensino Médio (1); } \\
\text { Técnico em Manutenção e Suporte em Informática } \\
\text { Integrado ao Ensino Médio- PROEJA (5); Técnico em } \\
\text { Administração Integrado ao Ensino Médio (1); Técnico } \\
\text { em Desenvolvimento de Sistemas Integrado ao Ensino } \\
\text { Médio (1). }\end{array}$ & $\begin{array}{l}\text { Permanecem } 2 \text { estudantes no } \\
\text { PROEJA; } 1 \text { em } \\
\text { Desenvolvimento de Sistemas; } \\
\text { e } 1 \text { em Administração. }\end{array}$ & $\begin{array}{l}\text { Evadiram } \\
4 \text { estudantes. }\end{array}$ \\
\hline Osório & 3 & & Permanecem 2 estudantes.* & $\begin{array}{l}\text { Evadiu } \\
1 \text { estudante. }\end{array}$ \\
\hline Porto Alegre & 5 & $\begin{array}{l}\text { Técnico em Administração Integrado ao Ensino Médio } \\
\text { - PROEJA (2); Técnico em Enfermagem (1); Técnico } \\
\text { em Segurança do Trabalho (1); Técnico em Transações } \\
\text { Imobiliárias (1). }\end{array}$ & \multicolumn{2}{|c|}{$\begin{array}{l}\text { Não obtivemos detalhamento sobre a situação } \\
\text { dos estudantes. }\end{array}$} \\
\hline Restinga & 5 & $\begin{array}{l}\text { Técnico em Eletrônica Integrado ao Ensino Médio (1); } \\
\text { Técnico em Recursos Humanos Integrado ao Ensino Médio } \\
\text { - PROEJA (3); Técnico Subsequente em Guia de Turismo } \\
\text { (1). }\end{array}$ & \multicolumn{2}{|c|}{$\begin{array}{l}\text { Não obtivemos detalhamento sobre a situação } \\
\text { dos estudantes. }\end{array}$} \\
\hline Sertão & 38 & $\begin{array}{l}\text { Técnico em Agropecuária Integrado ao Ensino Médio (29); } \\
\text { Técnico em Agropecuária Subsequente (2); Manutenção e } \\
\text { Suporte em Informática Integrado ao Ensino Médio (7). }\end{array}$ & Permanecem 18 alunos. & $\begin{array}{l}20 \text { alunos } \\
\text { solicitaram } \\
\text { transferência } \\
\text { durante o } \\
\text { primeiro ano } \\
\text { de curso. }\end{array}$ \\
\hline Viamão & 2 & $\begin{array}{l}\text { Técnico Subsequente em Serviços Públicos (1); Técnico } \\
\text { Subsequente em Administração (1). }\end{array}$ & Permanecem 2 estudantes & \\
\hline
\end{tabular}

Fonte: MÜLLING (2018).

* Não foram informados os cursos em que permanecem os estudantes dos campi Erechim e Osório. 
Apenas a partir de 2012, com a Lei no 12.711, instaurada (BRASIL, 2012a), é que os Institutos Federais passam a destinar cotas para ingresso de estudantes pretos, pardos e indígenas. Portanto, é a partir do processo seletivo de 2013 que se aplica tal legislação, e o levantamento de dados partiu desse ano. Consideramos, ainda, que esse seria o ano de ingresso dos alunos regulares ainda presentes em cursos técnicos integrados, cuja duração é de quatro anos em alguns campi e de três anos no Campus Sertão. Percebemos, nos quadros acima, a disparidade do número de matrículas realizadas pelo Campus Sertão, sendo essa a única unidade que disponibilizou para a pesquisa os dados sistematizados sobre o ingresso dos estudantes indígenas, contendo os registros de etnia e de terra indígena de origem, o aproveitamento no curso o motivo e/ou destino no caso de evasão.

Desse modo, escolhemos esse campus para realizar a etapa seguinte da pesquisa, a qual envolveu o trabalho de campo com entrevistas aos estudantes e vivências nas suas comunidades de origem. De acordo com os dados disponibilizados pelo Campus Sertão, em novembro de 2016, frequentavam os cursos técnicos de nível médio dezoito estudantes indígenas: onze no primeiro ano de seus cursos, cinco no segundo ano e dois no terceiro ano. A existência desses dados de forma sistematizada, sob a coordenação do Núcleo de Estudos Afro-Brasileiros e Indígenas (NEABI) do Campus Sertão, bem como o número de matrículas nos cursos ofertados, revela a existência de um trabalho diferenciado, mais atento às questões indígenas, tendo em vista que não se trata do único campus a estar geograficamente próximo das terras indígenas, conforme mapeamento registrado na Figura 1.

\section{Metodologia da Pesquisa}

O problema da investigação está em até que ponto se pode tolerar uma nova racionalidade proposta pelo próprio objeto de observação (KUSCH, 1976, p. 136).

As pesquisas desenvolvidas pelo filósofo argentino Rodolfo Kusch desafiam a compreensão da racionalidade proposta pelos indígenas da América, oposta à racionalidade científica. Conforme Kusch, compreender a racionalidade do então sujeito da pesquisa - os indígenas corresponde à frustração da proposta de uma investigação conforme a lógica ocidental de ciência.

Subordinando a investigação à possibilidade de uma comunicação, desaparece a relação entre observador e observado, e surge a possibilidade de uma convivência, na medida em que o observado propõe a sua racionalidade relacionada em sua própria razão de ser, em seu próprio projeto vital e cultural em uma perspectiva intercultural.
Nesse sentido, a concepção intercultural exposta aqui é fundamental, porque o indígena é visto como sujeito, é como sujeito que habita o mundo com seus símbolos, cria a sua economia e organiza as suas instituições, o seu modo de existir no mundo, o seu domicílio.

A presente pesquisa adotou uma abordagem qualitativa indutiva (BOGDAN; BIKLEN, 1994), buscando analisar as informações produzidas durante o levantamento de dados em conexão com os seus contextos de origem e circunstanciando-os nos processos históricos que envolvem os seus sujeitos.

A imersão ao campo da pesquisa ocorreu junto ao Instituto Federal de Educação do Rio Grande do Sul, Campus Sertão, à terra indígena kaingang de Ligeiro, em Charrua, e à terra indígena guarani de Mato Preto, em Erebango, ambas com estudantes matriculados no IFRS Campus Sertão. Dessas experiências, produzimos diários de campo com base em pressupostos da Antropologia, considerando as técnicas de observação participante e as entrevistas etnográficas.

Foram realizadas entrevistas etnográficas com os estudantes no Campus Sertão, seguindo um formato de roda de conversação coletiva, em que os participantes se manifestaram na medida de seu interesse.

Entrevistamos também dois servidores: um técnico em assuntos educacionais, coordenador do NEABI, e um vigilante, também membro do NEABI, que é o único servidor kaingang da instituição.

$\mathrm{Na}$ comunidade de Ligeiro, conversamos com o cacique e sua esposa. Em Mato Preto, além das conversações com uma de suas lideranças, pudemos participar de uma vivência cultural e religiosa seguida da partilha de alimentos.

Por meio de pesquisa bibliográfica (GIL, 2002, p.4345), foi construído o marco teórico preliminar, com o qual foram desenvolvidos os conceitos que fundamentam a análise, evidenciando a perspectiva descolonial como premissa essencial para a proposição de uma educação escolar indígena, sobretudo para a educação profissional, considerando as relações de poder imbricadas ao sistema econômico capitalista globalizado atualmente em vigência.

Na obra de Rodolfo Kusch (1976), buscamos a compreensão de uma filosofia ameríndia que sustenta os modos de viver e reinventar a existência dos povos originários. Patrício Arias (2010) traz apontamentos sobre o papel colonizador da racionalidade moderna e a importância da afetividade e da intuição como razões integrantes do ser humano na construção da ciência e do conhecimento entre os povos ameríndios.

Os documentos institucionais oficiais, quais sejam, Plano de Desenvolvimento Institucional (PDI), Projeto Pedagógico Institucional (PPI) e Projeto Pedagógico de 
Curso (PPC) pertencentes ao IFRS, foram analisados como aporte das concepções e práticas institucionais, à luz da interculturalidade crítica de Catherine Walsh (2009) e dos apontamentos de Nancy Fraser (2006) sobre reconhecimento e redistribuição.

Empregamos a metodologia de entrevista etnográfica como método autônomo em relação à etnografia clássica, buscando, na observação direta e participativa, a reflexão sobre os conhecimentos que os entrevistados expressam, conforme Guber (2001) e Pizarro (2014). A pesquisa não buscou analisar a conjuntura cultural dos indígenas em sua integralidade, posto o interesse em captar pontos específicos da organização social no que tange às relações de produção, trabalho e educação.

A entrevista etnográfica como "[...] um evento comunicativo construído progressiva e cooperativamente por ambos os interlocutores" (PIZARRO, 2014, p. 16), porém centrada no discurso do entrevistado, é coerente com a concepção de que os sujeitos envolvidos são produtores de conhecimentos e não objetos de conhecimento ou meros informantes (ARIAS, 2010). Os participantes não foram nominados pela questão ética de preservação de suas identidades, embora suas constituições identitárias, assim como os cargos que ocupam, sejam a própria validação de seus discursos. As falas dos entrevistados estarão registradas no texto identificadas pelos papeis desempenhados na instituição. Os questionamentos previamente formulados são flexíveis e abertos, objetivando captar as concepções elaboradas pelos entrevistados com menor intervenção das pesquisadoras. As conversações foram gravadas mediante a autorização prévia dos participantes, com o Termo de Consentimento Livre e Esclarecido ${ }^{2}$, que disponibiliza contato com as pesquisadoras e estabelece a possibilidade de remoção do consentimento a qualquer tempo. Os diálogos foram transcritos preservando a identidade dos sujeitos.

\section{A EXPERIÊNCIA DO IFRS - CAMPUS SERTÃo}

Sertão é um município de pouco mais de 6 mil habitantes, que não possui em seu território área indígena demarcada, mas está cercado por uma forte presença de aldeias indígenas, guarani e majoritariamente kaingang. Nessa região, há processos abertos para demarcação de terras, o que gera muitos e intensos conflitos com os demais trabalhadores rurais. No município e região, há também presença de quilombolas, porém com percentuais menos expressivos do que a presença indígena. A região possui propriedades centradas tanto no latifúndio como

\footnotetext{
2 A pesquisa está registrada na plataforma Brasil, em conformidade aos cuidados éticos exigidos.
}

na agricultura familiar, sendo o cultivo da soja, do milho e do trigo os mais expressivos, além da produção leiteira, criação de aves e suinocultura.

O Campus Sertão é agrícola, situado em uma área de mais de 200 hectares, o que torna muito dinâmicos os deslocamentos dos estudantes para presenciar as aulas nas instalações dos setores de produção. Isso dificulta o processo de autolocalização e familiarização com os ambientes. Para os indígenas, em especial, o deslocamento para o campus depende dos benefícios proporcionados pela assistência estudantil. Não apenas para esses, mas para todos os estudantes indígenas, os atrasos no recebimento desse auxílio, como ocorreu em alguns momentos dos últimos anos, são graves a ponto de ocasionar a desistência do curso pela total impossibilidade de deslocamento.

São ofertados cursos de graduação, de formação pedagógica, pós-graduação, PROEJA, concomitante, subsequente e o técnico integrado. Para os técnicos integrados (Agropecuária e Manutenção e Suporte em Informática), existe também a residência estudantil. Atualmente, são cerca de 300 estudantes internos, de segunda a sexta-feira. Nos arredores do campus, dadas as dificuldades de transporte, constituiu-se também uma rede de pousadas para estudantes, muitas das quais se configuram com estruturas físicas precárias.

Os cursos integrados que recebem mais candidatos indígenas têm duração de três anos e são diurnos (manhã e tarde). Para Informática, são ofertadas 30 vagas anuais e, para Agropecuária, 120 vagas anuais. Os estudantes têm contato com as disciplinas da formação técnica gradativamente, desde o primeiro ano do curso, juntamente com os componentes da formação básica.

De acordo com o site institucional ${ }^{3}$ e com as apresentações descritas nos Projetos Pedagógicos de Cursos, a origem do IFRS Campus Sertão é a Escola Agrotécnica Federal de Sertão, criada em 1957, dentro de uma concepção de produção generalizada de agronegócio. Nessa concepção, o campo é um espaço de produção, especialmente voltando-se à soja, ao milho e a outras monoculturas, ou mesmo à criação de animais. Esse modelo de produção baseado no ambiente como recurso produtivo, entre outros problemas, segue gerando êxodo rural. Isso ocorre porque os pequenos produtores não possuem condições de competitividade com os grandes latifúndios, os jovens migram para as cidades em busca de melhores condições de vida, ocasionando o envelhecimento da população rural, o fechamento de escolas rurais, entre outras graves consequências.

\footnotetext{
3 HISTÓRICO. Instituto Federal de Educação, Ciência e Tecnologia do Rio Grande do Sul Campus Sertão. Disponível em: https://ifrs.edu.br/ sertao/institucional/historico. Acesso em: 18 nov. 2016.
} 
Dentro da área do Campus Sertão, há um sítio arqueológico que apresenta uma antiga habitação kaingang, evidenciando a presença da etnia nesse território ao longo da história. Em 2009, foi criado no campus o NEABI, composto por professores, técnicos e estudantes, direcionado às atividades de Extensão. Segundo o seu coordenador ${ }^{4}$, em 2012, a gestão que assumiu o núcleo considerou que os projetos executados não alcançavam resultados significativos por serem pensados de dentro do campus para os indígenas, sem a sua participação ativa e efetiva. No momento em que surge a Lei de Cotas, portanto, começam a trabalhar com a problemática do acesso ao ensino, dando continuidade às ações de extensão e integrando membros da comunidade externa ao $\mathrm{NEABI}^{5}$.

Em 2013, começou a dar-se o ingresso de estudantes indígenas em Sertão, em virtude da Lei no 12.711 (BRASIL, 2012a) chamada Lei de Cotas. Observa-se que a maior procura indígena no campus é pelos cursos técnicos integrados ao ensino médio, sendo que há estudantes que estão em busca da conclusão do ensino médio apenas. Esses estudantes estão se inserindo em uma oferta de curso diferente de sua demanda e dificilmente encontrarão motivação para concluir os componentes da formação técnica e ter êxito no curso, especialmente se já apontarem interesses em alguma outra área de conhecimento. Nesses casos, o modelo de formação profissional ofertado distingue-se de sua demanda; ocorre a procura pelo ensino médio integrado porque muitas terras indígenas passam a ter escolas de ensino fundamental desde a década de 1990. Além disso, a oferta de nível médio nas escolas indígenas é recente e limitada na rede estadual do Rio Grande do Sul ${ }^{6}$. Embora seja condicional para o ingresso em cursos de graduação em que estão disponíveis as vagas por cotas, em muitas localidades, para concluir o ensino médio, o estudante necessita afastar-se de sua comunidade.

Quase a integralidade dos estudantes que procuram a instituição é kaingang. Em 2016, o primeiro guarani matriculou-se no curso técnico integrado em Agropecuária.

\footnotetext{
${ }^{4}$ Informações verbais de entrevista com o coordenador do NEABI, concedida à pesquisadora MÜLLING em 12 de agosto de 2016, em Sertão, RS, Brasil.

5 Essa participação torna-se mais complexa, à medida que envolve recursos para os deslocamentos de membros do campus para participação em reuniões junto as aldeias indígenas, mas tem sido almejada e atendida quando possível.

6 No mapeamento realizado considerando as terras indígenas do Rio Grande do Sul e a abrangência do ensino médio foram localizadas seis escolas estaduais ofertantes cujos projetos políticos pedagógicos foram formulados especificamente para o atendimento intercultural de estudantes indígenas: Instituto Estadual de Educação Indígena Ângelo Manhká Miguel - Terra Indígena Inhacorá; EEIEM Antonio Kasĩn-Mĩg - Terra Indígena Guarita; EEIEB Francisco Kajẽró - Terra Indígena Nonoai/Rio da Várzea; EEIKEM Cacique Sỹ Gre - Terra Indígena Nonoai; EEIEM Fág Kavá - Terra Indígena Serrinha; EEIEM Toldo Coroado - Terra Indígena Votouro.
}

No ano de 2013, como já foi mencionado, ocorreu no Campus Sertão o primeiro ingresso de indígenas após a implementação da Lei de Cotas. Nesse momento, não havia no instituto documento para a comprovação de renda com formato que suportasse a conjunção de fatores da subsistência indígena. Declaravam-se, portanto, pequenos agricultores, condição com a qual podem apresentar aproximações, mas que não reflete a realidade das populações originárias, incorrendo no risco da invisibilidade identitária. Felizmente, a gestão está buscando aprimorar esse processo.

A Política de Ingresso Discente (PID) do IFRS foi elaborada por meio de plenárias realizadas nos campi durante o ano de 2016 e aprovada pela Resolução no 53, do Conselho Superior (CONSUP), em 11 de julho de 2017. A aprovação de propostas prévias deu-se por votação entre os segmentos docente, discente e técnico administrativo. A dinâmica interna das plenárias e a adesão das comunidades foram conduzidas a critério e de acordo com as particularidades e possibilidades de cada campi, não havendo registros de participação ativa das lideranças indígenas nessa construção.

Esse documento registra o processo seletivo unificado por meio de provas de conhecimentos teóricos distribuídos nas áreas de Língua Portuguesa, Matemática, Ciências, História e Geografia. Para a participação nas provas, os candidatos que se autodeclararem indígenas deverão contar com o apoio das equipes dos Núcleos de Ações Afirmativas?

Para que o estudante seja considerado apto para concorrer às vagas reservadas para indígenas, a instituição baseia-se na Portaria no 849/2009, da Fundação Nacional do Índio (FUNAI). Ela aponta a necessidade de o candidato apresentar três documentos: uma autodeclaração, uma descrição detalhada de sua relação com a comunidade e uma declaração de, pelo menos, cinco membros da comunidade atestando a veracidade sobre o pertencimento étnico. O objetivo de se precaver contra a usurpação de direitos, por sua vez, torna-se um impeditivo para que membros exilados de comunidades indígenas tornem-se candidatos ao ingresso pela reserva de vagas.

Para o cálculo das vagas reservadas aos indígenas, a política estabelece, com amparo legal, a proporção dessa população no Estado, de acordo com o último censo do IBGE. No entanto, as populações indígenas do Rio Grande do Sul centram-se mais expressivamente em regiões e municípios específicos do Norte do Estado, como Charrua, em que a população indígena é de $43,9 \%$;

\footnotetext{
7 Compreende-se que essa indicação da política se refere especialmente aos NEABI's, mas pode envolver outros núcleos que pertencem às ações afirmativas institucionais: os Núcleos de Apoio a Portadores de Necessidades Específicas (NAPNE's) e os Núcleos de Estudo e Pesquisa em Gênero e Sexualidade (NEPGS).
} 
em Redentora, 39,5\%; em São Valério do Sul, 39,9\%; e em Engenho Velho, 34\% (IBGE, 2010). Nessas localidades, a presença indígena no arranjo produtivo local é mais significativa, mas o acesso por vagas reservadas seguirá a média estatal somada a de pretos e pardos.

Como medidas para apoio à permanência, estão estabelecidos o apoio acadêmico, psicossocial e, especialmente, financeiro para aqueles que se encontram em situação de vulnerabilidade social. A política estabelece a Comissão de Acompanhamento e Avaliação da Política de Ações Afirmativas (PAE) do IFRS, ao cargo da qual fica o acompanhamento de quaisquer ingressantes enquadrados como público-alvo das Ações Afirmativas (AA's), bem como a avaliação anual e o aprimoramento futuro do texto dessa política.

Como outros grupos mencionados na PAE (2013, p.3), os indígenas são enquadrados como vulneráveis pela sua condição de estigmatização étnica e constituem-se como público especial para esse setor que realiza, também, ações de caráter universal. Para os grupos em situação de vulnerabilidade é que cabem as ações pautadas pela busca da equidade de acesso, permanência e êxito do estudante na instituição. Entre essas ações, têm destaque os programas que trazem aos estudantes auxílios financeiros, componentes relevantes do quesito redistribuição para promoção da justiça social. Sobre esses auxílios, os participantes desta pesquisa revelaram muitas preocupações, tanto sobre cortes de recursos executados a partir da nova conjuntura política nacional atual como sobre as dificuldades dos indígenas em providências burocráticas que acompanham esses processos.

Portanto, a instituição dirige-se a ações efetivas de redistribuição, corroboradas por políticas federais de assistência estudantil em vigor até então, com o princípio do reconhecimento dos direitos dos povos indígenas, entre outros grupos. Conforme Fraser (2006), essas duas dimensões - reconhecimento e redistribuição - são necessárias e paralelas para a efetivação dos direitos das minorias ou de grupos segregados.

\section{A PRESENÇA de indígenas no CAMPUS SERTÃo}

Em 2016, visitamos o Campus Sertão, onde foram realizadas entrevistas etnográficas e conversações com estudantes indígenas e membros do NEABI - o coordenador, um servidor técnico em assuntos educacionais ${ }^{8}$

\footnotetext{
8 Atua há 6 anos no instituto. É Licenciado em Pedagogia pela Universidade Regional Integrada do Alto Uruguai e das Missões (URI), especialista em educação infantil e séries iniciais pela mesma instituição e mestre em Educação pela Universidade de Passo Fundo. Ao longo do texto, será citado como "coordenador do NEABI".
}

e um servidor kaingang ${ }^{9}$ atuante na função de vigilante e membro do NEABI de quem, em especial, registra-se o importante papel desempenhado. No âmbito desse texto, serão exploradas especialmente as falas do coordenador. Também realizamos visitas às comunidades mais próximas que possuem alunos matriculados no Campus Sertão: Ligeiro, comunidade kaingang, situada no município de Charrua, e Tekoá Arandu Verá Mato Preto, comunidade guarani situada no município de Erebango ${ }^{10}$. Segundo o IBGE (2010), as comunidades indígenas desses municípios contabilizam, respectivamente, 1.524 e 269 integrantes. Os estudantes indígenas permanecem então no Campus Sertão no regime de internato, saindo na sexta-feira com destino às suas comunidades e retornando na segunda-feira.

Os pais são indutores do trajeto escolar, responsáveis pelas escolhas dos cursos, assim como os caciques, desde a sua anuência para que as instituições visitem e divulguem seus processos seletivos nas comunidades. No entanto, a decisão final sempre pertence ao indivíduo que pesará as suas ações e as consecutivas interferências no cotidiano da comunidade.

Com os relatos coletados, compreende-se que não houve consulta aos povos indígenas sobre as modalidades e as terminalidades de cursos a serem ofertados pela instituição, mas apenas a informação às comunidades de que as vagas estavam disponíveis por meio do edital, após a conquista das cotas na Rede Federal de Educação Profissional, Científica e Tecnológica. Pontua-se que a criação de uma política pública ancorada no arranjo produtivo local, sobre a qual não há efetiva participação dos agentes locais e, sequer conhecimento por parte deles, tende a não se efetivar como prática democrática e socialmente justa. Na medida em que a criação das instituições de ensino visa a democratizar o acesso à educação, possibilitando equidade e condições de permanência àqueles que se encontram em situação de vulnerabilidade, o impedimento do acesso à informação constitui-se como um filtro antidemocrático.

\footnotetext{
9 Formou-se em 1999 como Técnico em Agropecuária pela Escola Técnica Agrícola. Cursou Magistério na Universidade de Passo Fundo, mestrado em Educação Ambiental na Universidade Federal do Rio Grande e, em 2016, ingressou no doutorado, também em Educação Ambiental, na FURG. Até a atualidade, apenas três indígenas formaram-se no mesmo curso técnico após esse servidor. Fez sua defesa de dissertação à academia na presença de um casal de Kuiãs, lideranças espirituais que cumprem também um papel político e organizativo. No IFRS, é concursado para atuação como vigilante.

${ }^{10}$ Com disputas territoriais desde 2006, foi declarada terra indígena em 2012 e, apenas em 2016, foi demarcada, de modo que seguem vivos e latentes muitos dos conflitos gerados nesse processo. Por determinação do Ministério Público Federal, a empresa Projetos, Supervisão e Planejamento Ltda (Prosul), contratada para tratar de medida compensatória pelo desgaste ambiental e social de obra realizada pela empresa Eletrosul, comprou a área e a escriturou à comunidade guarani. Os indígenas receberam também casas de madeira com saneamento básico e luz elétrica (Diário de campo, Mato Preto, novembro de 2016).
} 
Como primeiro ponto para possibilitar o acesso, o coordenador do $\mathrm{NEABI}^{11}$ aponta a necessidade de aproximação efetiva entre instituição e comunidades, pois apenas dessa forma é possível o acesso à informação de fato. Os métodos de divulgação oficiais (site, cartazes)" não são eficientes para alcançar as comunidades próximas. Estar apartado do pleno uso das tecnologias não é uma condição exclusiva dos indígenas, mas para eles é um fator acentuado, visto que as inovações tecnológicas em questão são aparatos oriundos de uma configuração cultural alheia a sua, mas que transcendem as fronteiras e estabelecem processos de encontro. Conforme Kusch, a tecnologia é um apêndice da cultura. Se considerarmos a técnica para determinada produção, precisamos considerar as pautas culturais que levaram a sua criação, pois se as pautas são outras, a produção resultante também será outra. "A tecnologia está, então, condicionada pelo horizonte cultural em que se produz" (KUSCH, 1976, p. 96 , tradução nossa $)^{12}$. A criação de objetos dá-se pela necessidade profunda gestada culturalmente. Segundo o autor, cultura implica uma localidade e pertence a uma comunidade, já a tecnologia transcende as fronteiras, é essencialmente dinâmica, como produto de uma época (KUSCH, 1976,). Nas palavras do coordenador do NEABI:

Então, nós temos que pegar isso e nós temos que ir à comunidade, nós temos que conversar com as pessoas, ouvir e dizer: 'Olha, eu sou lá do instituto, campus Sertão, nós temos isso, isso e aquilo', e eles vão começar a perguntar. E essa realidade, eu já trabalhei com pequeno agricultor, é a mesma coisa. Já trabalhei em periferia, é a mesma... Não vai ler o edital (Coordenador do NEABI, informação verbal) ${ }^{13}$.

Quando afirma que os interessados não irão ler o edital, o coordenador não está lhes tecendo uma crítica, mas imbuindo à instituição e seus agentes da tarefa de rever os seus meios, a fim de sanar a lacuna que se apresenta na recepção da informação. A circulação de informações por meio de editais é uma tecnologia alheia e antagônica às conformações indígenas: trata-se de uma ferramenta burocrática moderna produzida pela cultura ocidental e que se impõe às comunidades para efetivação de seus direitos.

Apontamos para a impessoalidade do processo de divulgação por meio de edital como um elemento que obstrui o trajeto da informação, visto que, para os

\footnotetext{
${ }^{11}$ Informação verbal em entrevista concedida pelo coordenador do NEABI à pesquisadora MÜLLING em 12 de agosto de 2016, Sertão, RS, Brasil.

12 "La tecnología está entonces condicionada por el horizonte cultural en donde se produce" (KUSCH, 1976, p. 96).

${ }^{13}$ Informação verbal em entrevista concedida pelo coordenador do NEABI à pesquisadora MÜLLING em 12 de agosto de 2016, Sertão, RS, Brasil.
}

grupos em questão, há necessidade de envolvimento como pressuposto para a confiança e o estabelecimento de parcerias. A flexibilização da impessoalidade dos procedimentos tem sido buscada através de vínculos afetivos e da busca por relações de confiança criadas especialmente a partir das visitas às comunidades. Reiterase, portanto, a importância da presença do servidor indígena como elo para o estabelecimento dessas relações, dada a sua etnia e o seu pioneirismo rumo à instituição. À medida que se divulga e se promove a instituição, cria-se um vínculo de responsabilidade quanto à veracidade do que está sendo ofertado. Para tanto, um indígena estar entre os agentes de divulgação da instituição certamente contribui para a aproximação e a confiança almejadas.

Segundo a Política de Ingresso Discente de 2017, não há diferenciação para indígenas na aplicação dos processos seletivos de ingresso do IFRS, defendida pelo coordenador na ocasião de sua entrevista como importante elemento da política de acesso:

O pessoal foca na prova como se fosse um elemento, a prova não é. Não decide nada fazer prova ou não fazer prova, e o fato é que o ingresso acontece. Na nossa ideia, conversando com as pessoas nós temos que ter o momento de diálogo, de acordo, de envolvimento nosso, onde que a gente possa mostrar o instituto. Porque hoje eles estão enxergando principalmente o campus Sertão. O instituto é muito maior. De repente, vai ter um cara de lá que vai dizer "eu quero ir para Canoas". Como funciona o campus Canoas, se ele vier para cá? Onde que ele vai morar? E aí começa a vir essas outras questões [...] (Coordenador do NEABI, informação verbal) ${ }^{14}$.

Os benefícios financeiros promovidos pela assistência estudantil são destacados como fundamentais para viabilizar o acesso e a permanência dos estudantes. Os atrasos e impeditivos burocráticos para o repasse dos recursos implicam não só em possíveis evasões, mas também no abalo das relações de confiança trançadas entre as comunidades e os agentes institucionais ${ }^{15}$. Grande parte das evasões no período entre 2013 e 2016, segundo o coordenador, deu-se por atrasos no repasse de benefícios. Uma vez que o estudante não tem como manter-se financeiramente no campus, retorna à comunidade. $\mathrm{Na}$ fala do coordenador:

\footnotetext{
${ }^{14}$ Informação verbal em entrevista concedida pelo coordenador do NEABI à pesquisadora MÜLLING em 12 de agosto de 2016, Sertão, RS, Brasil.

${ }^{15}$ Registram-se situações em que funcionários participantes do processo de divulgação institucional, por motivo de atraso no pagamento dos benefícios estudantis, emprestaram dinheiro para que os estudantes indígenas pudessem seguir frequentando o curso, visto que empenharam sua palavra quanto à disponibilidade de auxílio financeiro. Ainda que inadequada do ponto de vista da gestão pública, a situação denota a construção ética de uma rede de apoio para permanência dos estudantes indígenas.
} 
Tem um aluno que era bolsista do ensino e que estava dizendo "para mim hoje 10 reais valem 100, não tenho emprego, estou desempregado". Ele paga 15 reais por dia de transporte, o micro. Ele mora em Passo Fundo. Para chegar até Sertão, então. E ele ganha uma bolsa de 100 reais do ensino, pois agora tem os projetos de ensino. E ele falou 'esses 100 reais vão ser mil. Eu faço milagre com esse dinheirinho aí'. Eu sei que para muitas pessoas não é nada 100 reais, vão gastar aí numa festa. Mas "eu faço milagre com 100 reais". Então saem por isso. A maior parte da evasão é nossa responsabilidade institucional (Coordenador do NEABI, informação verbal, grifo nosso) ${ }^{16}$.

O coordenador do NEABI expõe a necessidade de que os agentes institucionais possam perceber a individualidade dos estudantes pertencentes aos grupos étnicos. Apesar de seguirem as orientações das lideranças e dos familiares, apresentam habilidades e dificuldades distintas, de modo que as escolhas e os interesses profissionais possam ser diversos. Ações institucionais que elucidem sobre os cursos ofertados e criem espaços para a reflexão sobre os contextos de atuação profissional podem ser pensadas como forma de acolhimento afetivo a esses jovens e adultos, que muitas vezes não analisaram em profundidade essas questões.

As demandas comunitárias são parâmetros importantes, mas não determinam por si só as trajetórias de formação dos sujeitos. A escolha profissional é do indivíduo, influenciada pelas necessidades da comunidade, mas ainda assim é uma escolha individual. Essa situação ilustra o dilema que é a necessidade indígena de dupla afirmação, como diz Kusch (1962, p. 12), de afirmação da identidade étnica e de sua cidadania individual.

De 2013 a 2016, ingressaram 42 estudantes nos cursos do IFRS em Sertão. Dentre esses, 21 alunos constavam como ativos em 2016/1, número que caiu para 15 em 2016/2, sendo elevada a evasão. No entanto, é preciso observar o caminho que percorrem os estudantes, pois muitos deles estão deixando pela primeira vez a aldeia, quando chegam ao internato do ensino médio integrado, para serem plenamente responsáveis individualmente por si mesmos. Considera-se muito relevante a preparação realizada para que os estudantes ingressem na instituição, mas, para as comunidades que se organizam por parentesco, o distanciamento da família representa grande estranhamento. Afastar-se da estruturação familiar que direciona o cotidiano, acolhendo amorosamente as individualidades e necessidades afetivas, para o indígena, compõe um duplo afastamento: familiar e comunitário.

\footnotetext{
${ }^{16}$ Informação verbal em entrevista concedida pelo coordenador do NEABI à pesquisadora MÜLLING em 12 de agosto de 2016, Sertão, RS, Brasil..
}

A experiência escolar prévia dos estudantes é um fator muito importante para a permanência ou evasão do ensino médio, pois contribuem para a leitura individual dessa nova situação. Na passagem do ensino fundamental específico para uma instituição federal, há uma acentuada ruptura na ordem de funcionamento do espaço escolar, tanto no que diz respeito às proporções espaciais e de infraestrutura quanto às metodologias de ensino e aprendizagem e aos modos de existência. Essa ruptura inevitavelmente causa estranhamentos, para os quais as estratégias de enfrentamento têm sido construídas nesses sujeitos - com mais ou menos intensidade - desde a infância em suas comunidades.

As desigualdades sociais impactam na qualidade das escolas rurais como um todo, pois os estudantes são aprovados para o ensino médio com grandes lacunas na aprendizagem. Isso faz com que os docentes do ensino médio tenham que fazer retomadas de conteúdo. Essa dificuldade não se restringe aos indígenas, mas potencializa-se neles, dadas as diferenças implicadas pela linguagem e pela mentalidade tradicional na construção do pensamento. Isso também ocorre porque suas escolas sofrem sobremaneira com a falta de recursos, além de estarem ainda em processo de estruturação em muitas aldeias ${ }^{17}$.

Especialmente por meio do NEABI do campus, buscam-se ações de promoção das relações étnico-raciais, a geração de dados de monitoramento e de avaliação dos estudantes indígenas, a oportunização de monitorias e o acompanhamento de egressos. A presença indígena aciona práticas interculturais pelas quais acontecem diálogos sobre o mundo e sobre as visões de mundo justapostas. O monitoramento de dados, segundo o coordenador do NEABI, ainda é aquém das necessidades, mas trata-se de um processo em desenvolvimento e ao qual seus atores estão atentos.

O critério afetivo como requisito para o estabelecimento de monitorias entre estudantes é uma estratégia às imposições do currículo racional e conteudista e das práticas docentes que o reproduzem de forma automatizada. Esse acompanhamento foi realizado em 2015, com continuidade no ano seguinte, porém com muita dificuldade de promover a efetiva presença dos envolvidos nos momentos de orientação. Dessa forma, dada essa resistência, não se apontam,

\footnotetext{
${ }^{17}$ Apenas a partir da década de 1990, garantido constitucionalmente o direito aos processos próprios de existência e aprendizagem, começam a emergir as formulações para a escola indígena. São estudos importantes sobre a temática os conduzidos por Bergamaschi: Nhembo'e: enquanto o encanto permanece!: processos e práticas da escolarização nas aldeias Guarani (2005), Educação Escolar Indígena: Um modo próprio de recriar a escola nas aldeias Guarani (2007a), Das escolas para índios às escolas indigenas (2007b), Processos e práticas educativas dos povos ameríndios no Brasil: um olhar a partir de pesquisas contemporâneas (2012).
} 
ainda, considerações resultantes deste acompanhamento no Campus Sertão $^{18}$.

Observa-se uma grande dificuldade de interação entre os indígenas e o grupo de colegas e com os próprios professores nas salas de aula. Por esse motivo, destacase a necessidade de ingressarem sempre em grupos ou, pelo menos, entre dois candidatos indígenas, de forma que possam entre si buscar o apoio e a compreensão inicial necessária. O compartilhamento de referenciais prévios facilita o processo de troca de informações e de compreensão e acolhimento da experiência do outro.

O coordenador comenta sobre a atitude dos estudantes indígenas em sala de aula:

[...] são mais reservados, perguntam menos; então, em sala de aula, a gente percebe assim, eles se agrupam num canto, dificilmente fazem perguntas, interagem inicialmente com os colegas. [...] Por exemplo, o aluno é quietinho em sala de aula, para ele falar o professor vai num canto. Ele faz tudo, mas ele não fala. Mas tu vais à comunidade dele, os caras não param de falar e riem de piada. Dai tu entendes o ambiente em que eles estão, e que é uma forma também de proteção, de cuidado entre eles, enfim (Coordenador do NEABI, informação verbal, grifo nosso) ${ }^{19}$.

A orientação do comportamento no ambiente é construída social e historicamente. Em sala de aula, são muito calados, fechados, mas, em outros espaços, revelase outra conduta. Em atividades escolares esportivas, estão inseridas as dimensões do sentir na medida das afetações produzidas no corpo, que se insere no processo de aprendizagem. Nessas, por exemplo, a desenvoltura dos estudantes é distinta, de modo geral participam e muito bem. O coordenador do NEABI relata que no campus há uma academia disponível para os estudantes, na qual interagem entre si e com os não indígenas melhor do que em sala de aula. Dessa forma, a partir de uma noção de integração da produção de conhecimento às esferas da vida, torna-se necessário pensar e aprimorar esses e outros - como a própria aldeia - como espaços educativos também, reconhecendo que a sala de aula não é espaço exclusivo da produção de conhecimento. Essa percepção sobre o comportamento dos estudantes reflete o seu estranhamento e, de certa forma, a opressão que inflige a eles a sala de aula. Podemos compreender essa atitude tímida se retomarmos as experiências escolares catequizantes e salvacionistas pelas quais passaram as

\footnotetext{
${ }^{18} \mathrm{Na}$ UFRGS, já existem estudos sobre a experiência da monitoria para estudantes indígenas, entre os quais indicamos Monitoria Indígena: A Diferença e a Igualdade, de Turcato e Farias (2011) e Indigenas estudantes nas graduações da UFRGS: movimentos de re-existência, de Doebber (2017).

${ }^{19}$ Informação verbal em entrevista concedida pelo coordenador do NEABI à pesquisadora MÜLLING em 12 de agosto de 2016, Sertão, RS, Brasil..
}

populações indígenas, em todo território nacional e no estado do Rio Grande do Sul.

Além disso, destaca-se a importância de gestores e docentes visitarem e reconhecerem as comunidades, conhecerem as famílias dos estudantes indígenas especialmente, mas também as famílias e as comunidades dos estudantes não indígenas, de modo a considerar em suas práticas as complexidades das realidades locais.

\section{CONSIDERAÇÕES FINAIS}

A presença indígena no Campus Sertão é um direito, porém cercado de complexidades, pois, conforme exemplo trazido por Kusch (1976, p. 118), há de se levantar em que medida as providências dadas àqueles que necessitam não lesionam sua dignidade: "Uma fonte de trabalho é sempre uma fonte de transculturação e, portanto, uma maneira sutil de destruir as vontades culturais da massa que utilizará a referida fonte para sua sobrevivência" 20 .

Dá-se a neutralização da vontade étnica pela necessidade imperiosa da obtenção do alimento e de outros recursos favoráveis à existência. $\mathrm{O}$ problema reside em saber com que eticidade se está tecnificando a mão de obra quando o objetivo de dirimir a fome está em uma atitude moderna útil e rentável, econômica e divorciada de uma ética interna e cultural, de um projeto coletivo étnico e sustentável e fortalecido.

Pondera-se que, reconhecido o direito constitucional aos processos próprios de existência indígena, é legítima a sua resistência à inserção no mundo capitalista e é legítima a sua luta por caminhar na construção de espaços alternativos ao sistema universalista vigente. Sua reexistência trata-se da reconfiguração da vida indígena em diálogo com o mundo, do movimento do que é mutável e imutável na cultura, sob a perspectiva de seus sujeitos.

Além disso, não se trata meramente de pedir acesso às vantagens dos avanços do ocidente mediante acesso à educação, nem de demonstrar que a sabedoria indígena detém também caráter científico, mas de demarcar a vigência das culturas indígenas na vida cotidiana da população latino-americana em uma perspectiva descolonial.

\section{REFERÊNCIAS}

ARIAS, P. G. Corazonar el sentido de las epistemologías dominantes desde las sabidurías insurgentes: para construir sentidos otros de la existencia (Primera Parte). Calle14: Revista de Investigación en el Campo del Arte, Bogotá, v. 4, n. 5, p. 80-94, 2010. https://doi.org/10.17163/soph.n8.2010.05

\footnotetext{
20 "Una fuente de trabajo es siempre una fuente de transculturaciión, y por lo tanto una forma sutil de destruir voluntades culturales de la masa que utilizará dicha fuente para su sobrevivencia".( KUSCH, 1976, p. 118).
} 
BERGAMASCHI, M. A. Educação escolar indígena: um modo próprio de recriar a escola nas aldeias Guarani.

Cadernos CEDES, Campinas, v. 27, n. 72, p. 197-213, 2007 a.

https://doi.org/10.1590/S0101-32622007000200006

BERGAMASCHI, M. A. Nhembo'e: enquanto o encanto permanece! Processos e práticas de escolarização nas aldeias Guarani. 2005. Tese (Doutorado em Educação) Programa de Pós-Graduação em educação, Faculdade de Educação, Universidade Federal do Rio Grande do Sul, Porto Alegre, 2005. https://doi.org/10.14507/epaa.v20n34. 2012

BERGAMASCHI, M. A. Processos e práticas educativas dos povos ameríndios no Brasil: um olhar a partir de pesquisas contemporâneas. Arquivos Analíticos de Políticas Educativas, [s. l.], v. 20, n. 34, p. 1-28, 2012. https://doi. org/10.14507/epaa.v20n34.2012

BERGAMASCHI, M. A.; SILVA, R. H. D. Das escolas para índios às escolas indígenas. Ágora, Santa Cruz do Sul, v. 13, n. 1, p. 124-150, 2007.

BOGDAN, R.; BIKLEN, S. K. Investigação qualitativa em educação: uma introdução à teoria e aos métodos. Porto: Porto, 1994.

BRASIL. Lei no 11.892, de 29 de dezembro de 2008. Institui a Rede Federal de Educação Profissional, Científica e Tecnológica, cria os Institutos Federais de Educação, Ciência e Tecnologia. Diário Oficial da União, Brasília, 30 dez. 2008. https://doi.org/10.18225/sispub.2019.7

BRASIL. Lei n ${ }^{\circ} 12.711$, de 29 de agosto de 2012. Lei de Cotas. Dispõe sobre o ingresso nas universidades federais e nas instituições federais de ensino técnico de nível médio e dá outras providências. Diário Oficial da União, Brasília, 30 ago. 2012a. https://doi.org/10.18316/2238-9024.15.4

BRASIL. Ministério da Educação. Conselho Nacional de Educação. Parecer $n^{0}$ 11, de 9 de maio de 2012. Diretrizes Curriculares Nacionais para a Educação Profissional Técnica de Nível Médio. Brasília: MEC, 2012b. https:/doi. org/10.11606/d.91.2017.tde-05012017-143040

BRINGMANN, S. F. Entre os índios do Sul: uma análise da atuação indigenista do SPI e de suas propostas de desenvolvimento educacional e agropecuário nos postos indígenas Nonoai/RS e Xapecó/SC (1941-1967). 2015. Tese (Doutorado em História) - Programa de Pós-Graduação em História, Departamento de História, Centro de Filosofia e Ciências Humanas, Universidade Federal de Santa Catarina, Florianópolis, 2015. https://doi.org/10.24873/j. rpemd.2017.11.026

DOEBBER, M. Indígenas estudantes nas graduações da UFRGS: movimentos de re-existência. 2017. Tese (Doutorado em Educação) - Programa de Pós-Graduação em Educação, Faculdade de Educação, Universidade Federal do Rio Grande do Sul, Porto Alegre, 2017.
FRASER, N. ¿Redistribuición o reconocimiento? Um debate político-filosófico. Madrid: Ediciones Morata, 2006.

GIL, A. C. Como elaborar projetos de pesquisa. São Paulo: Atlas, 2002.

GUBER, R. La entrevista etnográfica o el arte de la no directividad. In: GUBER, R. Etnografia, método, campo y reflexividad. Buenos Aires: Norma, 2001.

IBGE. Censo 2010. Rio de Janeiro: IBGE, 2010. Disponível em: https://censo2010.ibge.gov.br/. Acesso em: 26 dez. 2018. https://doi.org/10.5752/p.2175-5841.2012v10n28p1122

KUSCH, R. Geocultura del hombre americano. Rosario: Editorial Fundação Ross, 1976.

MÜLLING. J. C. Educação profissional com indígenas: possibilidades de corazonar e Melhor Viver. 2018. Dissertação (Mestrado em Educação) - Programa de Pós-Graduação em Educação, Faculdade de Educação, Universidade Federal do Rio Grande do Sul, Porto Alegre, 2018. https://doi. org/10.5380/jpe.v13i0.67496

PIZARRO, C. La entrevista etnográgica como práctica discursiva: análisis de caso sobre las pistas meta-discursivas y la emergencia de categorías nativas. Revista de Antropologia, São Paulo, v. 57, n. 1, p. 462-496, 2014.

TURCATO, R.; FARIAS, M. F. Monitoria indígena: a diferença e a igualdade. In: SALÃO DE ENSINO, 7., 2011, Porto Alegre. Trabalho apresentado [...]. Porto Alegre: UFRGS, 2011.

WALSH, C. Interculturalidade crítica e pedagogia decolonial: in-surgir, re-existir e re-viver. In: CANDAU, V. M. (org.). Educação intercultural na América Latina: entre concepções, tensões e propostas. Rio de Janeiro: 7 letras, 2009.

Recebido em: 1/2/2019.

Aprovado em: 12/7/2019.

Publicado em: 5/11/2019.

Endereço para correspondência:

Juliana da Cruz Mülling

Rua Dra. Maria Zélia Carneiro de Figueiredo, 870-A - Igara III 92412-240, Canoas, RS, Brasil

\section{Autoras:}

Juliana Da Cruz MülLing

Mestre em Educação pela Universidade Federal do Rio Grande do Sul (UFRGS).

Professora do Ensino Básico, Técnico e Tecnológico do Instituto Federal de

Educação, Ciência e Tecnologia do Rio Grande do Sul (IFRS/Campus Canoas).

Orcid: https://orcid.org/0000-0003-3469-5210

E-mail: juliana.mulling@canoas.ifrs.edu.br

Simone Valdete Dos Santos

Doutora em Educação pela Universidade Federal do Rio Grande do Sul e

Professora Associada IV da Faculdade de Educação e do Pós-Graduação da mesma Universidade (UFRGS).

Orcid: http://orcid.org/0000-0002-2523-006X

E-mail: simone.valdete@ufrgs.br

Endereço: Av. Paulo Gama s/n, prédio 12201, sala 817

90040-060, Porto Alegre, RS, Brasil 